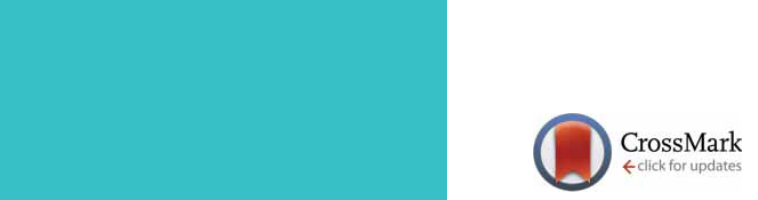

\title{
mMRC dyspnoea scale indicates impaired quality of life and increased pain in patients with idiopathic pulmonary fibrosis
}

\author{
Kaisa Rajala (10 ${ }^{1,2}$, Juho T. Lehto ${ }^{3,4}$, Eva Sutinen², Hannu Kautiainen ${ }^{5,6}$, \\ Marjukka Myllärniemi ${ }^{7}$ and Tiina Saarto ${ }^{1,2}$
}

Affiliations: ${ }^{1}$ Helsinki University Hospital, Comprehensive Cancer Center, Dept of Palliative Care, Helsinki, Finland. ${ }^{2}$ Faculty of Medicine, University of Helsinki, Helsinki, Finland. ${ }^{3}$ Dept of Oncology, Palliative Care Unit, Tampere University Hospital, Tampere, Finland. ${ }^{4}$ Faculty of Medicine and Life Sciences, University of Tampere, Tampere, Finland. ${ }^{5}$ Primary Health Care Unit, Kuopio University Hospital, Kuopio, Finland. ${ }^{6}$ Folkhälsan Research Center, Helsinki, Finland. ${ }^{7}$ University of Helsinki and Helsinki University Hospital, Heart and Lung Center, Dept of Pulmonary Medicine, Helsinki, Finland.

Correspondence: Kaisa Rajala, Helsinki University Hospital, Comprehensive Cancer Center, Dept of Palliative Care, Paciuksenkatu 21, PO box 180, FI-00290 Helsinki, Finland. Email: kaisa.rajalaQhhus.fi

ABSTRACT This study was undertaken to investigate idiopathic pulmonary fibrosis (IPF) patients' health-related quality of life (HRQoL) and symptoms in a real-life cross-sectional study. Our secondary aim was to create a simple identification method for patients with increased need for palliative care by studying the relationship between modified Medical Research Council (mMRC) dyspnoea scale, HRQoL and symptoms.

We sent a self-rating HRQoL questionnaire (RAND-36) and modified Edmonton Symptom Assessment Scale (ESAS) to 300 IPF patients; $84 \%$ of the patients responded to these questionnaires.

The most prevalent $(>80 \%)$ symptoms were tiredness, breathlessness, cough and pain in movement. An increasing mMRC score showed a linear relationship $(\mathrm{p}<0.001)$ to impaired HRQoL in all dimensions of RAND-36 and the severity of all symptoms in ESAS. Dimensions of RAND-36 fell below general population reference values in patients with $\mathrm{mMRC}$ score $\geqslant 2$. The intensity of pain in movement $(\mathrm{p}<0.001)$ and at rest $(\mathrm{p}=0.041)$, and the prevalence of chest pain $(\mathrm{p}<0.001)$ had a positive linear relationship to increased $\mathrm{mMRC}$ score.

An increasing mMRC score reflects impaired HRQoL and a high symptom burden. In clinical practice, the mMRC scale could be used for screening and identification of IPF patients with increased need for palliative care.

@ERSpublications

mMRC indicates impaired HRQoL and pain in IPF http://ow.ly/oRB430gIW7U

Cite this article as: Rajala K, Lehto JT, Sutinen E, et al. mMRC dyspnoea scale indicates impaired quality of life and increased pain in patients with idiopathic pulmonary fibrosis. ERJ Open Res 2017; 3: 00084-2017 [https://doi.org/10.1183/23120541.00084-2017].

Received: July 182017 | Accepted after revision: Nov 022017

Support statement: The Academy of Finland, the Sigrid Jusélius Foundation, the Foundation of the Finnish Anti-Tuberculosis Association and a governmental subsidy for health sciences research have supported Lung Factor research group. The sponsors had no role in the design of the study, the collection and the analysis of the data, or the preparation of the manuscript. Funding information for this article has been deposited with the Crossref Funder Registry.

Conflict of interest: Disclosures can be found alongside this article at openres.ersjournals.com

Copyright $\odot$ ERS 2017. This article is open access and distributed under the terms of the Creative Commons Attribution Non-Commercial Licence 4.0. 


\section{Introduction}

Idiopathic pulmonary fibrosis (IPF) is a chronic, progressive and severe disease of unknown cause, seen primarily in older adults [1]. Even with recent advances in pharmacological treatment, IPF is still a disease with a high morbidity and poor survival [2-4]. As the disease trajectory in IPF is comparable to many advanced malignant disorders, guidelines recommend early-integrated palliative care in addition to pharmacological treatment and referral for lung transplantation $[5,6]$.

Patients with IPF suffer from difficult symptoms, of which breathlessness and cough are the most common ones [7, 8]. In addition, there is some evidence that IPF patients frequently experience pain, although the location and mechanism of the pain have not been reported [7]. Comorbidities are frequently reported in IPF patients, as shown in a recent study, where $88 \%$ of the patients had at least one and $30 \%$ more than four other diagnoses [9]. The total number of comorbidities and especially the occurrence of cardiovascular disease are associated with increased mortality [9-12].

There exist a limited number of studies on the heath-related quality of life (HRQoL) of IPF patients in a real-life setting [13]. Most recent studies have either concentrated on pharmaceutical treatment or have included a very limited number of patients $[7,13]$. However, there are clear indications of a decreased HRQoL in IPF patients $[13,14]$.

The primary aim of this cross-sectional study was to describe the HRQoL and symptom burden among IPF patients derived from a national IPF registry (FinnishIPF). The secondary aim was the identification of patients with increased need for palliative care by investigating the relationship between dyspnoea score and HRQoL.

\section{Materials and methods \\ Study population}

The FinnishIPF study is a prospective national clinical registry study of IPF patients initiated in 2012. IPF diagnosis is made according to the American Thoracic Society/European Respiratory Society/Japanese Respiratory Society/Latin American Thoracic Society 2011/2015 criteria [1, 6]. In Finland, practically all IPF patients are initially evaluated in public hospitals (university and central hospitals). The FinnishIPF registry consists of all IPF patients from specialist centres who have given their informed consent to participate to the study. KAUNISTO et al. [2] have published a detailed description of the FinnishIPF study. Overall, $76 \%$ of confirmed IPF patients have given consent to participate to the study [2].

This study was initiated in April 2015, when all 300 patients registered to FinnishIPF study at that time were contacted and asked for a written informed consent to participate in this substudy. The questionnaires were sent to the patients with the consent form. The patients who did not respond within 2 weeks were contacted by telephone and reminded to answer to the questionnaire.

\section{Data collection and questionnaires}

Sociodemographic and disease characteristics were collected from patient records and by a separate questionnaire. Collected data included age, sex, date of birth, marital status, living conditions, education, physical activity, the need for help in daily activities, the date of IPF diagnosis, comorbidities and smoking status. The participants' exercise habits during the preceding 6 months $(\geqslant 30 \mathrm{~min}$ at least moderate-intensity leisure time physical exercise, i.e. causing breathless and sweating) were asked.

The specific questionnaires of symptoms and HRQoL were modified Edmonton Symptom Assessment Scale (ESAS), modified Medical Research Council (mMRC) dyspnoea scale and the RAND 36-Item Health Survey (RAND-36).

The ESAS is a self-rated, numeric-rating, symptom-based scale developed for assessing the symptoms of cancer patients [15]. ESAS measures different symptoms on a scale from 0 (no symptoms) to 10 (the worst possible symptoms) $[16,17]$. In this study, we used a modified version, including 12 questions on symptoms, one question on general wellbeing and a standardised body diagram on which patients could mark the areas of pain.

The mMRC scale is a self-rating tool to measure the degree of disability that breathlessness poses on day-to-day activities on a scale from 0 to 4: 0 , no breathlessness except on strenuous exercise; 1 , shortness of breath when hurrying on the level or walking up a slight hill; 2, walks slower than people of same age on the level because of breathlessness or has to stop to catch breath when walking at their own pace on the level; 3, stops for breath after walking $\sim 100 \mathrm{~m}$ or after few minutes on the level; and 4, too breathless to leave the house, or breathless when dressing or undressing $[18,19]$.

The RAND-36 [20] is a general HRQoL measurement tool, for which Finnish general population reference values exist [21]. The Short Form-36, which is commonly used in IPF patients, is similar to RAND-36 [21] 
It is divided into eight health concepts, as explained by HaYs et al. [20] and AALTO [21], with scale from 0 to 100 (lower score meaning worse HRQoL). The concepts are: "physical functioning" (10 questions from ability to move and exercise to the ability to take care of personal hygiene), "role physical" (four questions on role limitations due to physical health), "bodily pain" (two questions), "general health" (five questions), "vitality" (four questions on energy level and tiredness), "social functioning" (two questions), "role emotional" (three questions on role limitations due to emotional problems) and "mental health" (five questions on anxiety, depression and mood) during the past 4 weeks [20, 21].

\section{Statistics and ethical aspects}

The data are presented as mean $\pm \mathrm{SD}$ or $\mathrm{n}(\%)$. The statistical significance for the hypothesis for linearity across groups in RAND-36 domains and symptoms were determined by ANCOVA and logistic regression analysis with an appropriate contrast (orthogonal polynomial). In the case of violation of the assumptions (e.g. non-normality), a bootstrap-type test was used. The normality of the variables was tested by using the Shapiro-Wilk W-test. Stata 14.1 (StataCorp LP, College Station, TX, USA) was used for the analysis.

The ethical committee of Helsinki University Central Hospital (Helsinki, Finland) approved this study $(381 / 13 / 03 / 01 / 2014)$. Permission to screen hospital registries for patients with IPF was approved by the Finnish National Institute for Health and Welfare (Dnro THL/1161/5.05.01/2012). All patients who participated to this study gave a written informed consent to participate this substudy.

\section{Results}

Of 300 registered patients, 47 were excluded: 42 did not want to participate or did not answer our questionnaire; one received lung transplantation and one was found not to be IPF patient, so these two also were excluded; three patients died before they answered.

\section{Patient characteristics}

The patient characteristics are shown in table 1. The mean duration of IPF at the time of the study entry was 3.9 years. At least one comorbidity was reported in $79 \%(n=200)$ and more than two comorbidities in $30 \%(n=77)$ of the patients, respectively. $37 \%$ of the patients had performed at least moderate-intensity leisure time physical exercise for $\geqslant 30$ min a week during the last 6 months, whereas $21 \%$ had not been engaged in any physical exercise. A majority (65\%) of the patients did not need help in everyday life,

$\begin{array}{lc}\text { TABLE } 1 \text { Patient characteristics } & \\ \text { Age years } & 74 \pm 9 \\ \text { Males } & 165(65 \%) \\ \text { Duration of IPF years } & 3.9 \pm 2.5 \\ \text { Education years } & 10 \pm 4 \\ \text { Living alone } & 70(28 \%) \\ \text { Working } & 22(9 \%) \\ \text { Smoking status } \# & \\ \text { Smokers } & 26(10 \%) \\ \text { Ex-smokers } & 109(43 \%) \\ \text { Never-smokers } & 118(47 \%) \\ \text { FVC }{ }^{\#} \text { L } & 3.0 \pm 0.9 \\ \text { FVC }{ }^{\#} \text { of predicted } & 83 \pm 17 \% \\ \text { Comorbidities } & 105(42 \%) \\ \text { Hypertension } & 64(25 \%) \\ \text { Coronary heart disease } & 50(20 \%) \\ \text { Diabetes } & 46(18 \%) \\ \text { Heart insufficiency } & 43(17 \%) \\ \text { COPD } & 41(16 \%) \\ \text { Cancer } & 24(10 \%) \\ \text { Asthma } & 93(37 \%) \\ \text { Others } & 53(21 \%) \\ \text { No comorbidities } & 1.8 \pm 1.5 \\ \text { Comorbidities } n & \end{array}$

Data are presented as mean \pm SD unless otherwise stated. IPF: idiopathic pulmonary fibrosis; FVC: forced vital capacity; COPD: chronic obstructive pulmonary disease. ${ }^{\#}$ : smoking status and FVC were recorded at the time of diagnosis, and other factors at the time of questionnaire; " : including three patients with lung cancer. 
whereas $26 \%$ had received assistance in their daily routines. The remaining patients (9\%) did not receive help but considered themselves to be in need of it.

\section{mMRC for breathlessness}

The severity of breathlessness on exertion reported by mMRC score was 0 (no breathlessness) in 33 (13\%), 1 (breathless when hurrying or walking up a hill) in 88 (35\%), 2 (breathless when walking slower than people of same age or has to stop when walking) in 75 (30\%), 3 (breathlessness stops walking after $\sim 100 \mathrm{~m}$ or a few minutes) in $34(13 \%)$ and 4 (breathless when dressing or not able to leave the house) in $23(9 \%)$ of the patients.

\section{RAND-36 for HRQoL}

The different dimensions of HRQoL measured by RAND-36 are presented in table 2. There was a linear relationship between impaired HRQoL and all RAND-36 dimensions and a higher mMRC score (linearity $\mathrm{p}<0.001$ ) (figure 1). All HRQoL dimensions of RAND-36 were significantly impaired in patients with mMRC 2-4 as compared to the general population except "bodily pain", which was significantly below the general population level only in patients with mMRC score 4 (figure 1). Physical dimensions ("physical functioning" and "role physical") were the most impaired ones. "Role physical" derives from four questions in the questionnaire and reflects limitations in everyday life due physical health problems [20, 21].

\section{ESAS for symptoms}

The prevalence and mean intensity of symptoms as measured by ESAS are shown in table 2. There was positive linear relationship between the intensity of all symptoms in ESAS questionnaire and increasing mMRC breathlessness score (figure 2).

\section{Pain}

A striking increase in pain intensity in movement $(\mathrm{p}<0.001)$ and, to lesser extent, at rest $(\mathrm{p}=0.041)$ was found with an increased mMRC score (figure 2). The prevalence of pain in different locations of body diagram according to mMRC groups is shown in table 3. The prevalence of chest pain and increasing mMRC score showed a positive linear relationship (linearity $\mathrm{p}<0.001$ ).

\section{Discussion}

This was a cross-sectional, real-life study of the quality of life and symptoms of IPF patients. Our results show that increased breathlessness as measured by the mMRC questionnaire is related to impaired HRQoL and symptom burden. In addition to breathlessness and cough, pain in movement was detected in a majority of the patients. However, only chest pain had a linear relationship with increased mMRC breathlessness score. We suggest that pain and, more importantly, chest pain, may be an underdiagnosed symptom of IPF.

In our study, the HRQoL of IPF patients with at least moderate shortness of breath (mMRC $\geqslant 2$ ), was impaired in all areas of HRQoL, especially physical function, when compared to the Finnish general

TABLE 2 Symptoms by Edmonton Symptom Assessment Scale (ESAS) questionnaire and

health-related quality of life by RAND 36-Item Health Survey (RAND-36)

\begin{tabular}{|c|c|c|c|c|}
\hline ESAS & Prevalence & Score ${ }^{\#}$ & RAND-36 & Score \\
\hline Tiredness & $95 \%$ & $4.7 \pm 2.6$ & Social functioning & $72 \pm 28$ \\
\hline Shortness of breath & $88 \%$ & $4.9 \pm 3.0$ & Mental health & $72 \pm 20$ \\
\hline Cough & $85 \%$ & $4.1 \pm 2.9$ & Bodily pain & $62 \pm 27$ \\
\hline Pain in movement & $82 \%$ & $3.7 \pm 2.9$ & Vitality & $53 \pm 23$ \\
\hline Dry mouth & $79 \%$ & $3.8 \pm 3.0$ & Role Emotional & $51 \pm 42$ \\
\hline Insomnia & $67 \%$ & $2.8 \pm 2.8$ & Physical functioning & $47 \pm 29$ \\
\hline Pain in rest & $66 \%$ & $2.2 \pm 2.3$ & General health & $40 \pm 19$ \\
\hline Depression & $63 \%$ & $2.1 \pm 2.4$ & Role Physical & $31 \pm 39$ \\
\hline Anxiety & $61 \%$ & $2.1 \pm 2.4$ & & \\
\hline Constipation & $57 \%$ & $1.9 \pm 2.5$ & & \\
\hline Loss of appetite & $48 \%$ & $1.6 \pm 2.3$ & & \\
\hline Nausea & $40 \%$ & $1.1 \pm 1.8$ & & \\
\hline Wellbeing & $90 \%$ & $4.4 \pm 2.4$ & & \\
\hline
\end{tabular}



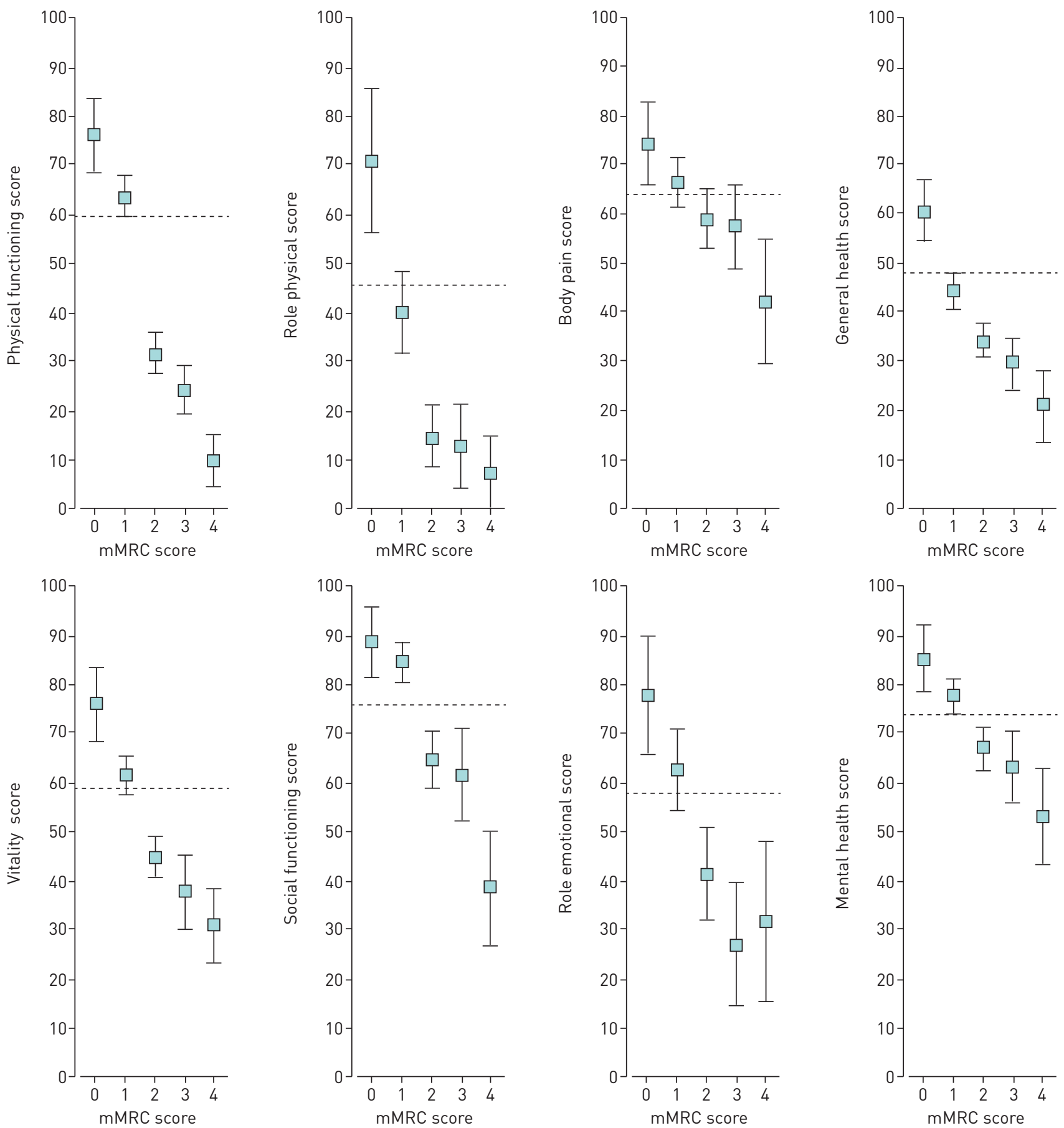

FIGURE 1 Health-related quality of life measured by the RAND 36-Item Health Survey according to modified Medical Research Council (mMRC) dyspnoea scale groups. Data are presented as mean values with $95 \%$ confidence intervals. Values adjusted for age, sex, comorbidities, education and living status. Dashed lines mark Finnish general population levels.

population [21]. Our findings are in line with an American Internet survey of 220 IPF patients in which HRQoL was measured with PROMIS-29 [22]. A correlation between mMRC scores and all domains except sleep disturbance was found [22]. In a small, cross-sectional, longitudinal study of 32 Japanese IPF patients, lower scores were reported in all eight domains (HRQoL questionnaire SF-36) when compared to the general population [13]. Similarly, in another small observational validation study of 34 IPF patients, a decline was seen in seven of the eight measured domains of SF-36 compared to sex- and age-matched controls [14]. That particular study also showed correlation between baseline dyspnoea index and five SF-36 components: physical functioning, general health perceptions, vitality, social functioning and mental health [14]. Even though there was a significant correlation between baseline dyspnoea index and pulmonary 


$\left.{ }^{10}\right]$ Wellbeing $\begin{gathered}\text { Pain in } \\ \text { movement }\end{gathered} \quad \begin{gathered}\text { Pain in } \\ \text { rest }\end{gathered} \begin{gathered}\text { Shortness } \\ \text { of breath }\end{gathered} \quad$ Cough $\quad$ Tiredness
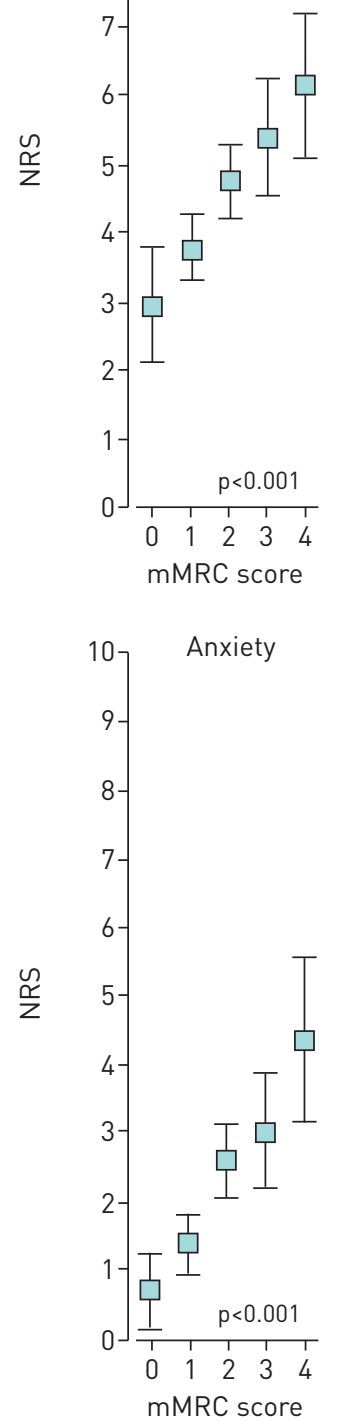

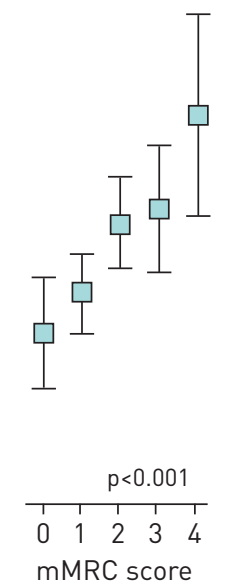

Insomnia

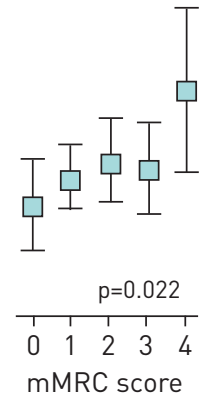

Dry mouth<smiles>COC(C)OC</smiles><smiles>[TeH][TeH]</smiles>

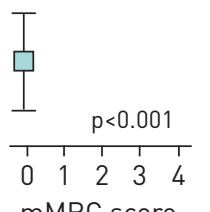

Loss of appetite

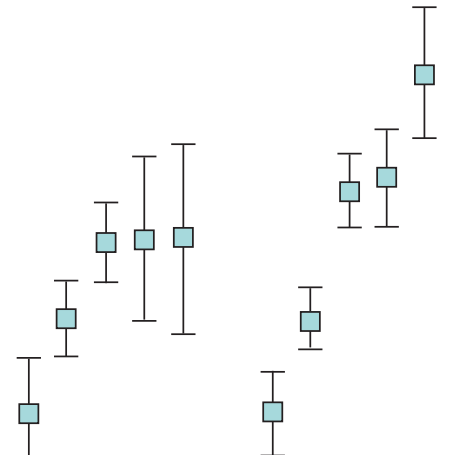

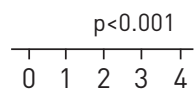

mMRC score

Constipation

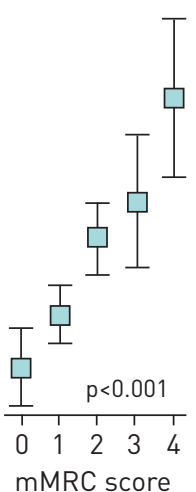

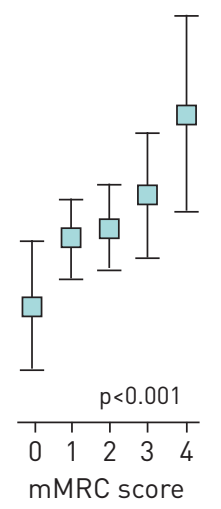
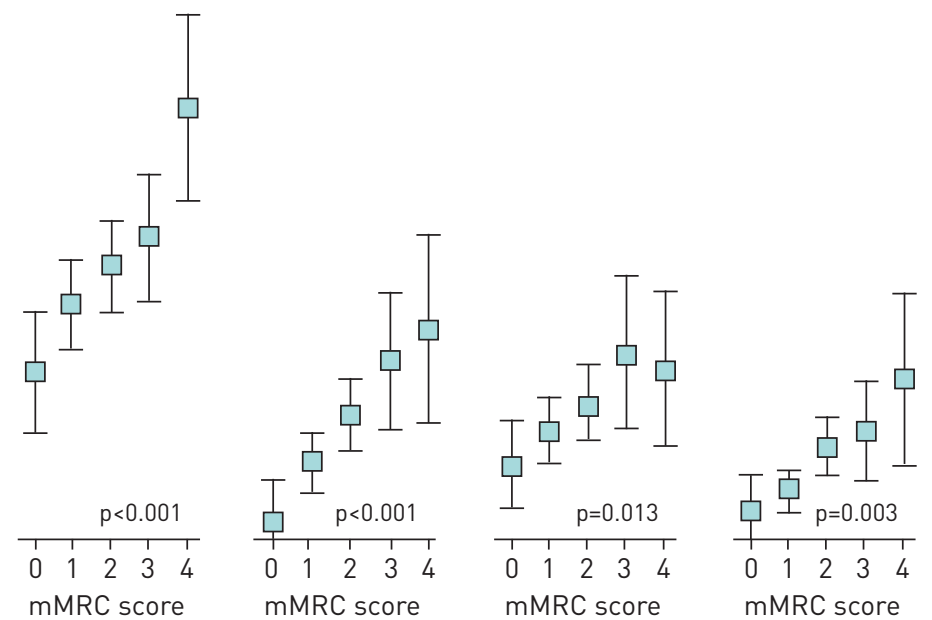

FIGURE 2 Symptoms measured by Edmonton Symptom Assessment Scale according to modified Medical Research Council (mMRC) dyspnoea scale groups. Data are presented as mean numeric rating scale (NRS) values with $95 \%$ confidence intervals. Values adjusted for age, sex, comorbidities, education and living status.

function parameters, dyspnoea index seemed to predict HRQoL more sensitively than pulmonary function parameters [14]. Dyspnoea in daily living, measured by mMRC, is also stronger prognostic parameter than most physiological markers in the diagnostic phase of IPF [23]. NishiYama et al. [23] showed that low arterial oxygen saturation in a 6-min walk test and mMRC score were the strongest predictors of IPF patient's survival.

In line with the American Internet survey, increasing mMRC score was related to the symptom burden of IPF patients in our study [22]. The three most common symptoms in our study were tiredness, shortness of breath and cough, which are in line with earlier findings [7]. Interestingly, however, pain in movement was the next most common symptom reported by the majority of our patients, and pain in rest was the sixth most common symptom, present in two thirds of the patients. In a Swedish register study of oxygen-dependent interstitial lung disease patients, pain was reported in 51\% of the patients [7]. Similarly to our findings, Yount et al. [22] demonstrated an association between dyspnoea severity in mMRC score and intensity of pain. In another small observational study, no correlation between baseline dyspnoea 


\begin{tabular}{|c|c|c|c|c|c|c|}
\hline & \multicolumn{5}{|c|}{ mMRC score } & \multirow[t]{2}{*}{ p-value } \\
\hline & 0 & 1 & 2 & 3 & 4 & \\
\hline Subjects & 33 & 88 & 75 & 34 & 23 & \\
\hline Head and neck & 9 (27\%) & 17 (19\%) & $16(21 \%)$ & $7(21 \%)$ & 9 (39\%) & 0.66 \\
\hline Chest & $4(12 \%)$ & $19(22 \%)$ & $35(47 \%)$ & $10(29 \%)$ & $11(48 \%)$ & $<0.001$ \\
\hline Upper limbs & $7(21 \%)$ & $24(27 \%)$ & $20(27 \%)$ & 3 (9\%) & $8(35 \%)$ & 0.41 \\
\hline Stomach & $2(6 \%)$ & $11(12 \%)$ & $18(24 \%)$ & $4(12 \%)$ & $4(17 \%)$ & 0.27 \\
\hline Back & $8(24 \%)$ & $38(43 \%)$ & $38(51 \%)$ & $11(32 \%)$ & $7(30 \%)$ & 0.56 \\
\hline Pelvis & 8 (24\%) & $28(32 \%)$ & $26(35 \%)$ & $10(29 \%)$ & $10(43 \%)$ & 0.56 \\
\hline Lower limbs & 18 (55\%) & 45 (51\%) & $32(43 \%)$ & $16(47 \%)$ & $15(65 \%)$ & 0.77 \\
\hline Extensive $^{\text {I }}$ & $5(15 \%)$ & $18(20 \%)$ & $20(27 \%)$ & $3(9 \%)$ & $8(35 \%)$ & 0.94 \\
\hline
\end{tabular}

mMRC: modified Medical Research Council dyspnoea scale. \#: for linearity, adjusted for age, sex, comorbidities, education and living status; ": four or more of the seven pain areas marked by the patient.

index and pain index was found [14]. These differences could be related to different stage of the disease in different study populations.

In our study, every third patient reported chest pain, which also had linear relationship to the intensity of breathlessness measured by mMRC. Unspecified thoracic pain has been reported in pulmonary sarcoidosis and chronic obstructive pulmonary disease but, to our knowledge, this is the first study to report chest pain in IPF $[24,25]$. The exact aetiology of chest pain in IPF falls beyond the scope of our study, and should be an aim of further studies. However, as the relationship between chest pain and breathlessness was maintained after adjusting for comorbidities and age, the results suggest that chest pain may be a symptom related to IPF itself. This finding should be taken into account when considering diagnostic tests and treatment strategies for patients with advanced IPF.

\section{Study limitations}

The cross-sectional nature of the study limits our results to a single time-point and does not allow us to describe the changes in symptoms or HRQoL over time. Our cohort may be subjected to some selection bias, as some patients at a very advanced stage of the disease or close to death are likely to be lost from the cohort. Another limitation is that although the diagnosis of IPF was made by pulmonologists according to international guidelines, there was no central confirmation of the diagnoses. The strength of our study is a relatively large population of IPF patients in different phases of disease trajectory, evaluated by several assessment tools in real-life setting, and a high response rate.

\section{Conclusions}

Pain is a relatively common symptom in IPF. In particular, chest pain is related to increasing mMRC score. This could indicate a causal relationship between chest pain and progressive IPF, but further studies are necessary to confirm and explain these findings. Our results show that mMRC not only reflects breathlessness in patients with IPF but indicates HRQoL and overall symptom burden. The HRQoL was significantly deteriorated and symptom burden rose in patients with mMRC score $\geqslant 2$. Thus, mMRC could be used as a simple screening tool for palliative care needs of IPF patients.

\section{Acknowledgements}

We are grateful for the patients that consented to participate in this study. The authors express gratitude to the participants of the FinnishIPF consortium: R. Kaarteenaho (University of Oulu, Oulu, Finland), S. Saarelainen (Tampere University Hospital, Tampere, Finland), H. Kankaanranta (Seinäjoki Central Hospital, Seinäjoki, Finland), A. Böök (Satakunta Central Hospital, Pori, Finland), E.R. Salomaa (University of Turku, Turku, Finland), J. Kaunisto (University of Turku, Turku, Finland), U. Hodgson (Helsinki University Central Hospital, Helsinki, Finland) and M. Purokivi (Kuopio University Hospital, Kuopio, Finland). The authors are also immensely grateful to the numerous pulmonary physicians who have contributed to the study by including patients and seeking informed consent: J. Vaden (Hämeenlinna Hospital, Hämeenlinna, Finland), M. Pekonen (Kanta-Häme Central Hospital, Hämeenlinna, Finland), H. Tapanainen (Hyvinkää Hospital, Hyvinkää, Finland), H. Lajunen (Jämsä Hospital, Jämsä, Finland), A. Saarinen (Seinäjoki Central Hospital, Seinäjoki, Finland), U. Suuronen (Etelä-Karjala Central Hospital, Lappeenranta, Finland), L. Lammi (Päijät-Häme Central Hospital, Lahti, Finland), K. Lehtonen (Pohjois-Kyme Hospital, Kouvola, Finland), J. Männistö (Kymeenlaakso Central Hospital, Kotka, Finland), I. Salmi (Pohjois-Karjala Central Hospital, Joensuu, Finland), M. Torkko (Etelä-Savo Central Hospital, Mikkeli, Finland), P. Torkko (Etelä-Savo Central Hospital, Mikkeli, Finland), M. Erkkilä (Savonlinna Central Hospital, Savonlinna, Finland), H. Andersen (Vaasa Central Hospital, Vaasa, Finland), J. Jaakkola (Pietarsaari Hospital, Pietarsaari, Finland), H. Rinne (Keski-Pohjanmaa Central Hospital, Kokkola, 
Finland), M-L. Alho (Rauma Hospital, Rauma Finland), M. Pietiläinen (Satkunta Central Hospital, Pori, Finland), T. Toljamo (Lapland Central Hospital, Rovaniemi, Finland), M. Palomäki (Kainuu Central Hospital, Kajaani, Finland), E. Nylund (Kainuu Central Hospital, Kajaani, Finland), E. Ahonen (Kainuu Central Hospital, Kajaani, Finland), P. Impola (Oulaskangas Hospital, Oulainen, Finland), S. Saviaro (Länsi-Pohja Central Hospital, Kemi, Finlan), L. Pusa (Raasepori Hospital, Raasepori, Finland), S. Vilkman (Porvoo Hospital, Porvoo, Finland), H. Ekroos (Porvoo Hospital, Porvoo, Finland), P. Vuori (Lohja Hospital, Lohja, Finland), J. Hedman (Etelä-Karjala Central Hospital, Lappeenranta, Finland), M. Lahti (Jokilaakso Hospital, Jämsä, Finland) and A. Mursu (City Hospital of Oulu, Oulu, Finland).

K. Rajala, J.T. Lehto, E. Sutinen, T. Saarto and M. Myllärniemi designed this study. K. Rajala, E. Sutinen and M. Myllärniemi were responsible for data collection. All authors analysed the data, drafted the manuscript, and read and approved the final manuscript. K. Rajala takes responsibility for the whole work.

A part of the results presented in this article have been presented as an abstract and poster at the 15th world Congress of the European Association for Palliative Care, May 18-20, 2017, Madrid, Spain.

\section{References}

1 Raghu G, Collard HR, Egan JJ, et al. An official ATS/ERS/JRS/ALAT statement: Idiopathic pulmonary fibrosis: Evidence-based guidelines for diagnosis and management. Am J Respir Crit Care Med 2011; 183: 788-824.

2 Kaunisto J, Kelloniemi K, Sutinen E, et al. Re-evaluation of diagnostic parameters is crucial for obtaining accurate data on idiopathic pulmonary fibrosis. BMC Pulm Med 2015; 15: 92-015-0074-3.

3 Richeldi L, du Bois RM, Raghu G, et al. Efficacy and safety of nintedanib in idiopathic pulmonary fibrosis. $N$ Engl J Med 2014; 370: 2071-2082.

4 King TE, Bradford WZ, Castro-Bernardini S, et al. A phase 3 trial of pirfenidone in patients with idiopathic pulmonary fibrosis. N Engl J Med 2014; 370: 2083-2092.

5 Behr J, Richeldi L. Recommendations on treatment for IPF. Respir Res 2013; 14: Suppl. 1, S6-9921-14-S1-S6.

6 Raghu G, Rochwerg B, Zhang Y, et al. An official ATS/ERS/JRS/ALAT clinical practice guideline: Treatment of idiopathic pulmonary fibrosis. An update of the 2011 clinical practice guideline. Am J Respir Crit Care Med 2015, 192: e3-e19.

7 Ahmadi Z, Wysham NG, Lundstrom S, et al. End-of-life care in oxygen-dependent ILD compared with lung cancer: A national population-based study. Thorax 2016; 71: 510-516.

8 Bajwah S, Higginson IJ, Ross JR, et al. The palliative care needs for fibrotic interstitial lung disease: a qualitative study of patients, informal caregivers and health professionals. Palliat Med 2013; 27: 869-876.

9 Kreuter M, Ehlers-Tenenbaum S, Palmowski K, et al. Impact of comorbidities on mortality in patients with idiopathic pulmonary fibrosis. PLoS ONE 2016; 11: e0151425.

10 Hyldgaard C. How does comorbidity influence survival in idiopathic pulmonary fibrosis? Respir Med 2014; 108: 647-653.

11 Nathan SD. Prevalence and impact of coronary artery disease in idiopathic pulmonary fibrosis. Respir Med 2010; 104: 1035-1041.

12 Hubbard R. The association between idiopathic pulmonary fibrosis and vascular disease: a population-based study. Am J Respir Crit Care Med 2008; 178: 1257-1261.

13 Tomioka H, Imanaka KF, Hashimoto KF, et al. Health-related quality of life in patients with idiopathic pulmonary fibrosis - cross-sectional and longitudinal study. Intern Med 2007 2007; 46: 1533-1542.

14 Martinez TY. Evaluation of the short-form 36-item questionnaire to measure health-related quality of life in patients with idiopathic pulmonary fibrosis. Chest 2000; 117: 1627-1632.

15 Bruera E, Kuehn N, Miller MJ, et al. The Edmonton Symptom Assessment System (ESAS): a simple method for the assessment of palliative care patients. J Palliat Care 1991; 7: 6-9.

16 Chang VT, Hwang SS, Feuerman M. Validation of the Edmonton Symptom Assessment Scale. Cancer 2000; 88: 2164-2171.

17 Hannon B, Dyck M, Pope A, et al. Modified Edmonton Symptom Assessment System including constipation and sleep: validation in outpatients with cancer. J Pain Symptom Manage 2015; 49: 945-952.

18 Mahler DA, Wells CK. Evaluation of clinical methods for rating dyspnea. Chest 1988; 93: 580-586.

19 Bestall JC, Paul EA, Garrod R, et al. Usefulness of the medical research council (MRC) dyspnoea scale as a measure of disability in patients with chronic obstructive pulmonary disease. Thorax 1999; 54: 581-586.

20 Hays RD, Morales LS. The RAND-36 measure of health-related quality of life. Ann Med 2001; 33: 350-357.

21 Aalto A. RAND-36 terveyteen liittyvän elämänlaadun mittarina : Mittarin luotettavuus ja suomalaiset väestöarvot [RAND-36 health-related quality of life: meter reliability and Finnish population values]. Tutkimuksia/Sosiaali- ja terveysalan tutkimus- ja kehittämiskeskus 1999; 101: 1-78.

22 Yount SE, Beaumont JL, Chen SY, et al. Health-related quality of life in patients with idiopathic pulmonary fibrosis. Lung 2016; 194: 227-234.

23 Nishiyama O, Taniguchi HF, Kondoh YF, et al. A simple assessment of dyspnoea as a prognostic indicator in idiopathic pulmonary fibrosis. Eur Respir J 2010; 36: 1067-1072.

24 Janssen DJ, Wouters EF, Parra YL, et al. Prevalence of thoracic pain in patients with chronic obstructive pulmonary disease and relationship with patient characteristics: A cross-sectional observational study. BMC Pulm Med 2016; 16: 47-016-0210-8.

25 Hendrick DJ, Blackwood RA, Black JM. Chest pain in the presentation of sarcoidosis. Br J Dis Chest 1976; 70: 206-210. 